From these symptoms and signs Dr. Burder concluded that the patient's great and immediate distress was due to dropsy of the pericardium, and that therefore paracentesis should at once be done. The operation was performed by the house-surgeon (Mr. Thomas Elliott) by means of Dienlafoy's pneumatic aspirator, the needle being inserted between the fifth and sixth ribs, and an inch to the right of the nipple. Forty-two ounces of clear, pale, straw-coloured fluid were drawn off. Towards the close of the operation the apex of the heart was felt to strike once or twice against the needle, but it ceased on placing the needle more horizontally. It is here worth stating, especially from a practical point, that for cases of paracentesis the needles of the aspirator might with advantage be graduated. At times it is extremely difficult to estimate how far the needle has penetrated, as it was in this case, where there was a considerable amount of external œedema.

The patient expressed himself as easier after the operation, but it was not till some hours after that there was any marked improvement.

On April 29th the patient looked much better; the face was of a better bue, breathing much easier, and he could lie on either side or on his back. Respiration 50 per minute; pulse feeble. Dulness over base of left lung diminished, and not extending so high upwards. Respiration over same region much more audible, with some moist sounds. Area of heart's dulness definable, sounds not so audible as immediately after tapping. On April 30th the improvement was greater, the pulse was much stronger, and the general anasarca had gone down a good deal. On May 2 ad he said that he had slept but little the last two nights, on account of continued coughing, but the next night he slept much better. On May 3 rd he cauld lie on either side, but said that if he did so he must be well over on his face, but he preferred lying on the left side. Heartsounds indistinct; lower extremities more odematous.

From this time he continued to improve, and on May 31st the dropsy had entirely disappeared and the heart's apex could be seen and felt beating about an inch below the left nipple. The area of dulness was definable and greatly diminished; the sounds were louder, and an indistinct bruit, apparently louder towards the base, but not carried up along the large bloodvessels, could be heard. There was still a line of dulness posteriorly at right base, where also the respiration was feeble. After this be sat up daily, but if he made any exertion he suffered at once from dyspncea and palpitation. The heart's beat was less distinct and was more to the outer side of left nipple than before; sounds irregular and confused.

On July 6 th he was discharged as an out-patient, much improved and able to move about more freely.

\section{STANLEY HOSPITAL, LIVERPOOL.}

OLD OMENTAL HERNIA; STRANGULATION OF COLON; SAC ACQUIRED.

(Under the care of Mr. J. Kellett Shrith.)

THE following notes should be read in conjunction with those that appeared of a similar case at this hospital on the 18th of December last.

A distiller, aged fifty-three, was admitted on August 31st, 1875, suffering from an old inguinal hernia of the left side, which had been irreducible for four days previously. The tumour was very large, and be complained of pain in the lower part of the abdomen, which was moderately distended. He romited also. All efforts at reduction by taxis having failed, the operation of herniotomy was performed on September 1st, under a spray of carbolic acid lotion, which was used throughout. As the neck of the sac was not discoverable from the outside, much less the constrict. ing tissue, an opening was made, and a very narrow neck found low down in the scrotum. Much fluid escaped, and about a pound and a half of omentum was disclosed, in the folds of which a few inches of large intestine were concealed (presumably the transverse colon). This was only slightly reddened, and was easily reduced. The omentum was absolutely uninjured, and was eventually reduced after much difficulty. The sac was next stripped up from the scrotum, and put back into the abdomen after the omentum, several catgut ligatures being applied to arrest the hæmorrhage caused by this procedure. Sutures of carbolised waxed silk were used, and a drainage-tube of caoutchouc placed in the upper and lower extremities of the wound respectively. The dressing consisted of many-folded carbolised gauze, which was persistently used, and changed under the spray. Suppuration, however, was not prevented in the scrotal portion of the wound. Nothing else of note occurred during the convalescence, except an attack of bronchitis, to which he is liable, and which probably delayed the healing of the wound. He was discharged quite well, as far as concerned the hernia, but slightly bronchitic, seven and a half weeks after operation.

Remarks.-This case, and the very similar one reported in THE LaNCET of Dec. 18th, were both surrounded with most favourable circumstances before and during operation, and were probably not exposed to any real risk during the aftertreatment. Before operation, the fact that each strangulation occurred in an old sac, and the shortness of the period during which this symptom was unrelieved, were points which mitigated as far as possible the gravity of the cases. During operation, the discovery of uninjured parts, and the maintenance of antiseptic conditions during their exposure, no doubt contributed much to avert any accidental intraperitoneal complications. The omentum might easily have been tied and cut off, which would certainly have been done had it not been that these masses were maintained antiseptic throughout. Moreover, it was not expected that their return into the abdomen would result in any harm. The stripping up and reduction of the scrotal portion of the sac, in one instance, was done in the hope that as near an approach as practicable to a radical cure might be made by the blocking of the internal ring. This was only imperfectly achieved in the other (congenital) case, on account of the inseparable attachment of the sac to the testicle. The stitching together of the neck of the sac was only regarded as a temporary measure, as experience has already shown that permanent occlusion of the neck of the sac by suture is seldom attained.

\section{HÛPITAL ST. LOUIS, PARIS.}

SMALL SARCOMA OF THE ORBIT; EXOPHTHALMIA; ENUCLEATION OF THE EYEBALL; RRYSIPELAS ; DEATH ; AUTOPSY.

(Under the care of M. PEAN.)

J. B-, aged twenty-seven, was admitted Sept. 8th, 1875. He was a well-nourished and healthy-looking man. His family history was good, and he denied ever having had syphilis. In the month of May, 1871, while a soldier, he had acute double conjunctivitis. This attack was soon cured by appropriate treatment. Three or four months later on his friends noticed that his right eye protruded rather more than his left one. 'This protrusion, however, caused him no inconvenience, and his sight remained equally good in both eyes. At about this time he attended at the Val de Grâce Hospital, where he was put under treatment by Dr. Perrin, consisting of iodide of potassinm and mercurial frictions. His condition was not ameliorated after this treatment, and from that moment his eye became more and more prominent.

On admission the eyelids were red and inflamed, but there was no cedema. On the right side the eyelids were still capable of closing over the globe. The patient had command over the extrinsic muscles of the eyeball, which acted well. The conjunctiva was highly injected, and there was slight odema at the internal angle; cornea bealthy; size of pupil normal; the iris contracted well under the influence of light. The patient could count fingers at six inches, and he could read No. 12 Jäger. The pharynx and the nasal foseæ presented nothing abnormal. The general health was good.

Sept. 12th.-Being unable to obtain satisfactory knowledge as to the nature and the cause of the mischief, $M$. Péan made a curved incision, parallel to the border of the eyelid. On introducing the finger into the incision, a tumour of small dimensions, and rather hard, was felt rest- 